JMI Vol. 43 No. 1, Juni 2021

METAL INDONESIA

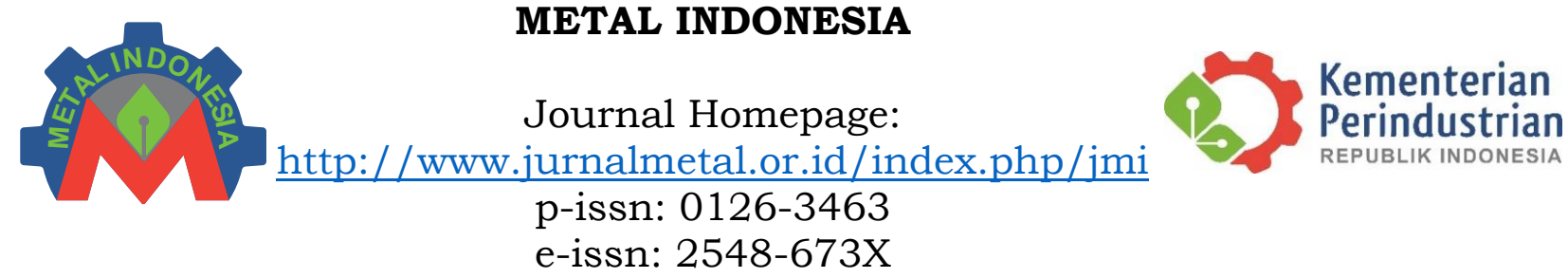

\title{
CHARACTERIZATION OF IRON REMOVAL PROCESS PRODUCTS FROM ATMOSPHERIC LATERITIC ORE LEACHING SOLUTION BY USING 20 and 25\% OF CALCIUM CARBONATE
}

\author{
Muhammad Nibras Azza Adhikara ${ }^{1}$, Reza Miftahul Ulum ${ }^{1}$, Alfian Ferdiansyah Madsuha ${ }^{1}$, \\ Faizinal Abidin ${ }^{2}$
}

${ }^{1}$ Departemen Teknik Metalurgi dan Material, Universitas Indonesia, Depok

${ }^{2}$ Pusat Teknologi Pengembangan Sumberdaya Mineral - BPPT, Gedung Geostech 820 Puspiptek, Serpong

E-mail : reza.ulum@ui.ac.id

\begin{abstract}
Electric vehicles become the alternative to solve the climate change and global warming problems by providing a more eco-friendly and sustainable source of energy. As the demand for sustainable vehicles increased, the functionality of batteries become crucial. One of the important aspects inside the batteries is nickel. Nickel plays a big role in lithium-ion batteries by delivering greater amounts of energy density with a higher storage capacity, which means it provides bigger efficiency to the batteries. Yet, the attempt of optimizing nickel extraction remains a challenge. Therefore, nickel extraction process of lateritic ore with high efficiency is investigated by using hydrometallurgy process, specifically the iron removal process in atmospheric condition in mixed hydroxide precipitates (MHP) route. The reagent solution of (20\% w/w and $25 \% \mathrm{w} / \mathrm{w})$ calcium carbonate $(\mathrm{CaCO} 3)$ at $\mathrm{pH}(1,2,3)$ were utilized as additive in this process. The precipitates resulted from PLS were characterized by x-ray diffraction (XRD) and Scanning Electron Microscopy - Energy Dispersive X-Ray (SEM-EDS), while the filtrates were investigated by Inductively Coupled Plasma-Optical Emission Spectrometry (ICP-OES). Analysis based on precipitates demonstrates that the acid neutralization process took place with a sufficient amount of iron in the precipitates with the least amount of nickel. In addition, all $\mathrm{pH}$ and concentration of precipitates qualitatively illustrate the same neutralization process involving calcium and sulfur. From the results of filtrate through ICP testing in this study, pH 1 for both $20 \%$ and $25 \%$ concentration provides the lowest recovery rate alongside the smallest ppm compare to $\mathrm{pH} 2$ and 3; thus, the iron precipitates in the formation of iron sulfide and/or iron sulfate. Overall, the optimum parameter is $25 \%$ of calcium carbonate, $\mathrm{pH} 1,90^{\circ} \mathrm{C}$ for 2 hours of agitation to reduce the amount of iron in the solution.
\end{abstract}

Keywords : Nickel laterite, iron removal, calcium carbonate

\section{INTRODUCTION}

Indonesia is rich in the oxide form of nickel ore or also known as lateritic nickel. The lateritic nickel ore consists of two groups; the limonite which contains less than $1.5 \%$ of nickel, and saprolite which has nickel of more than $1.5 \%$ ("Mineral Commodity Summary: Nickel Statistic and Information" 2020). Lateritic ore deposits can be easily found in Indonesia due to surficial condition, hence, weathering, geochemical and morphological factors that change ultramafic rocks or igneous rocks (Haryadi 2017). The Ministry of Energy and Mineral Resources of Indonesia has announced the ban policy on the export of low-grade nickel, which contains less than $1.7 \%$ of nickel ("Bijih Nikel Tidak Boleh 
Diekspor Lagi per Januari 2020" 2019). On the other hand, high-grade nickel is more economically beneficial by using pyrometallurgy. However, low-grade nickel ore which is lateritic ore is difficult to be processed and one of the alternatives is by using hydrometallurgy (Solihin 2018). Here, the attempt of optimizing nickel extraction remains a challenge.

Today's society demands, which is based on environmental approach in reducing the possibilities of earth destruction, has increased the production of electricity (DiChristopher 2018). One of the crucial aspects of electric cars is batteries, especially lithium-ion batteries. Nickel plays a big role in lithium-ion batteries by delivering greater amounts of energy density with a higher storage capacity, which means it provides bigger efficiency to the batteries (Kamali-Heidari, Kamyabi-Gol, and Ataie 2018).

Therefore, the nickel extraction process of lateritic ore with low grade with high efficiency must be investigated especially for Indonesia's current technology and natural resources. Shifting the process from the current method, pyrometallurgy into hydrometallurgy of leaching and mixed hydroxide precipitates (MHP) would beneficial in developing lithium-ion batteries for electric vehicles.

As the leaching process is finished, separation of nickel, cobalt, iron, manganese, and other acid-soluble minerals must occur. Separation selectively of nickel and cobalt needs to be the priority in this process; thus precipitation is the product. The obstacle of the process is the excessive iron content in PLS, which needs to be eliminated without involving nickel and cobalt concentration. The iron removal process takes two consecutive processes, iron removal 1 and iron removal 2 (Kamali-Heidari, Kamyabi-Gol, and Ataie 2018). The first stage is responsible for removing iron, chromium, and aluminum content excessively with the neutralization process, while the second stage is responsible for removing any remainder of those metals. Topkaya et al. has utilized $\mathrm{CaCO}_{3}$ with a percentation of $25 \%$ w/w slurry and $12.5 \% \mathrm{w} / \mathrm{w}$ slurry in the reagent for the first and second stages of iron removal, respectively. For the first stages, a $\mathrm{pH}$ of 2.5 is the best option at the temperature of $90^{\circ} \mathrm{C}$ for 2 hours. Based on XRD investigation, the main precipitation comes in bassanite, while the other phases are gypsum, hematite, goethite, and small amount of calcite (Mbedzi et al. 2017). The second stage of iron removal was observed at a $\mathrm{pH}$ of 4.25 at the temperature of $90^{\circ} \mathrm{C}$ for 1 hour (Mbedzi et al. 2017). After the iron removal process is finished, nickel and cobalt can be precipitated by using magnesia and followed by manganese removal in the end (Mbedzi et al. 2017). Therefore, this research is devoted to investigate the concept of nickel and cobalt extraction from lateritic ore and to optimize their parameter process.

The research is useful to determine the proper and efficient parameter of $\mathrm{pH}$, and concentration with the appropriate reagent concentration for iron removal process in nickel and cobalt downstream from atmospheric leaching process of lateritic nickel ore by using sulfuric acid.

\section{RESEARCH METHODOLOGY}

Materials that will be used in this research consist of lateritic nickel ore and pregnant leach solution (PLS) based on sulfuric acid. The leaching process was completed at Pusat Teknologi Pengembangan Sumberdaya Mineral, Agency for the Assessment and Application of Technology (BPPT). The reaction was performed at the atmospheric extraction process using $2 \mathrm{M}$ of sulfuric acid $\left(\mathrm{H}_{2} \mathrm{SO}_{4}\right)$ at the temperature, time, and agitation speed are $95^{\circ} \mathrm{C}, 6$ hours, and $300 \mathrm{rpm}$, respectively. After sample (lateritic nickel ore was mixed with PLS), the chemical composition of initial condition was investigated by ICP. In mixed hydroxide precipitation of nickel and cobalt process, the reagent used was calcium carbonate from Merck with the composition of $20 \% \mathrm{w} / \mathrm{w}$ ratio and $25 \% \mathrm{w} / \mathrm{w}$ ratio. The reagent was prepared by mixing pure calcium carbonate powder with aquades to create homogeneous slurry. PLS was prepared by pouring $250 \mathrm{~mL}$ sulfate into a beaker glass. PLS is stirred and heated at a temperature of $90{ }^{\circ} \mathrm{C}$ for 30 minutes. The top of the beaker is closed by using a petri dish to prevent excessive evaporation process. Afterward, the titration process was performed using a concentration of $20 \%$ and $25 \%$ reagent at $\mathrm{pH} \mathrm{1,2}$, and 3. The $\mathrm{CaCO}_{3}$ reagent was poured down to the PLS solution slowly until the projected $\mathrm{pH}$ had been achieved. The process took about 2 hours with increasing the rpm speed to 
adjust with the viscosity. The decantation was conducted to separate filtrate and precipitate. Then, the precipitates are dried on a hot plate for 1 hour and pulverized by mortar to achieve the powder for XRD and SEM-EDS characterization. The ICP-OES was performed to determine the concentration of the metal element in the filtrate.

\section{RESULT AND DISCUSSION}

Leaching solution initial elements are investigated, listed in Table 1 below. It can be seen that the Fe element is the highest amount in the solution, followed by $\mathrm{Al}, \mathrm{Ni}, \mathrm{Cr}$, and $\mathrm{Mn}$.

Table 1. Initial composition of PLS

\begin{tabular}{|c|c|}
\hline Sample & $\begin{array}{c}\text { PLS (Elements) } \\
\mathrm{mg} / \mathrm{L}\end{array}$ \\
\hline $\mathrm{Fe}$ & 2092.71 \\
\hline $\mathrm{Ni}$ & 83.99 \\
\hline $\mathrm{Cr}$ & 72.28 \\
\hline $\mathrm{Al}$ & 274.68 \\
\hline $\mathrm{Mn}$ & 35.91 \\
\hline
\end{tabular}

In order to investigate the effectiveness of process, the precipitate and filtrate after leaching were investigated. The XRD measurement was performed to observe the material structure and its crystallography. The XRD of precipitates resulted from $20 \%$ and $25 \% \mathrm{CaCO}_{3}$ at varied $\mathrm{pH}$ is displayed in Figure 1.

The XRD graphs of all precipitates illustrate a similar pattern of elements. Most of the elements are obtained in calcium sulfate $\left(\mathrm{CaSO}_{4}\right)$ formation. The formation of calcium sulfate is due to the neutralization process that happen during the titration process. Here, the neutralization process took a significant amount of calcium to bond with sulfur. Therefore, in all $\mathrm{pH}$, they consist of different forms of calcium sulfate, such as anhydrite, bassanite, and gypsum. The changes of its form due to the hydration process during the titration. It is supported by research done by Kose et al. 1, (Köse and Topkaya 2011) that the majority of the phases in XRD are bassanite and gypsum.
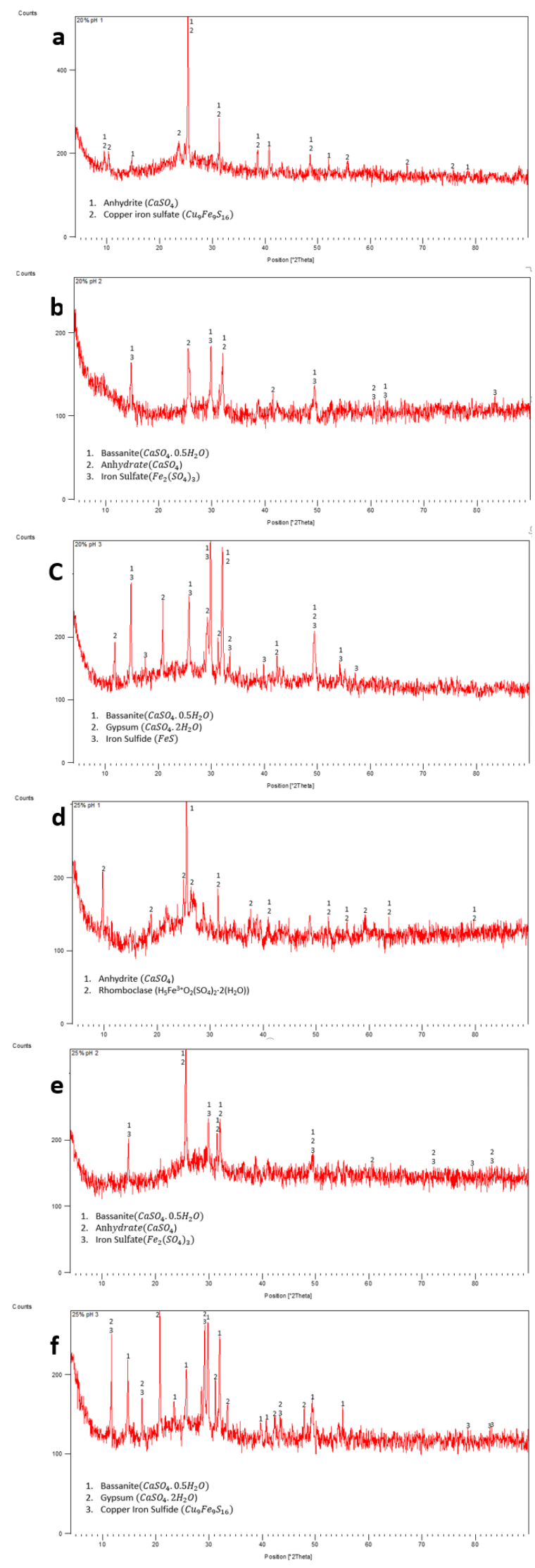

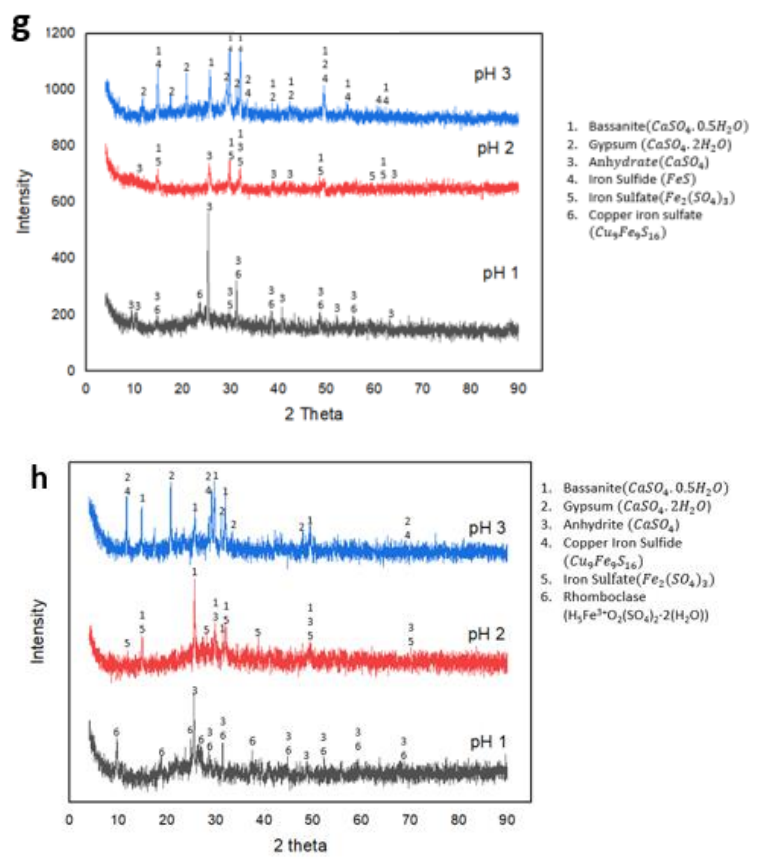

Figure 1. XRD of precipitates produced at concentration $20 \% \mathrm{CaCO} 3$ at $\mathrm{pH} 1$ (a), $\mathrm{pH} 2(\mathrm{~b})$, and $\mathrm{pH} 3(\mathrm{c})$ and $25 \% \mathrm{CaCO} 3$ at $\mathrm{pH} 1$ (d), $\mathrm{pH}$ 2(e), $\mathrm{pH} 3(\mathrm{f}), 20 \%$ XRD compilation $(\mathrm{g})$, and $25 \% \mathrm{XRD}$ compilation (h)

In this study, unhydrated form of calcium sulfate $\left(\mathrm{CaSO}_{4}\right)$ is found, however, the longer agitation might accommodate the transformation into hydrated forms. The XRD results of concentration $20 \%$ and $25 \% \mathrm{CaCO}_{3}$ at $\mathrm{pH} 1$ show that $\mathrm{CaSO}_{4}$ comes mostly in anhydrites form while the iron comes in sulfate formation. The $\mathrm{pH} 1$ is not sufficient to change the ferric state of iron, and thus, the iron is still in the formation of sulfate. It is also observed that at $\mathrm{pH} 2$ and $\mathrm{pH} 3$, bassanite $\left(\mathrm{CaSO}_{4} \cdot 0.5 \mathrm{H}_{2} \mathrm{O}\right)$ peak dominate the results. Typical bassanite was formed with a higher amount of water moles, whereas the gypsum was precipitated the gypsum was precipitated with a small amount of water.

The second most detected compound is iron sulfate. The ferric state changes process cannot be seen from the XRD data. However, the literature has reported that the iron precipitates is not only in the form of ferric state but in sulfate state (Köse and Topkaya 2011). It is not fit with the mildly acidic condition ( $\mathrm{pH}>1.5)$, whereas $\mathrm{Fe}$ (II) is quite stable and $\mathrm{Fe}$ will (III) easily hydrolyze to ferric hydroxide $\mathrm{FeO}(\mathrm{OH})$. Consequently, iron sulfate precipitates do not change its form, bonding with the calcium carbonate. Therefore, in this research, most of the XRD graph does not show any hydrolysis product of ferric hydroxide but instead iron sulfate or iron sulfide. These changes can happen in iron removal stage 2 , whereas additional calcium carbonate is needed. In addition, longer agitation might help to oxidize $\mathrm{Fe}$ (II) to $\mathrm{Fe}$ (III), because the oxidation is possible at low $\mathrm{pH}$ values if there is oxidants such as oxygen. However, the process is very slow. Theoretically, Fe(II) or ferrous have small possibilities to transform into ferrous hydroxide or ferric(iii). Fe(III) or ferric has the greatest probabilities to transform into ferric hydroxide in lower $\mathrm{pH}$. Thus, calcium carbonate only helps to neutralize the PLS.

The EDS data provides quantitative evidence of elements in the precipitates. As shown Table 2 and 3, the most abundant elements are oxygen and sulfur. Most of samples have high tendency to show calcium sulfate formation, such as anhydrite and bassanite. The formation of calcium sulfate is due to the neutralization process that happen during the titration process (Safitri et al. 2018). Here, calcium from $\mathrm{CaCO}_{3}$ bond with the sulfur from leaching reagent of $\mathrm{H}_{2} \mathrm{SO}_{4}$ and form calcium sulfate Nickel and iron have the probability to precipitates in the formation of carbonates. However, in the experiments, similar with calcium, iron has shown the more tendency to bond with sulfur, to form iron sulfate. Moreover, the hydroxide precipitation will occur rapidly from the supersaturated solution condition and produce a very fine non-crystalline residue. The greater the $\mathrm{pH}$, the greater the intensity of calcium sulfate in the XRD. Three different observation areas was taken for EDS investigation, all of the precipitates show the high amount of iron element. It can be seen that $\mathrm{pH} 1$ of PLS $25 \% \mathrm{CaCO}_{3}$ shows the highest average iron content compared to that of others.

It is noteworthy that nickel is are also found in the precipitates, however the amount of $\mathrm{Ni}$ is neglectable due to the small quantity. Therefore, it is not detected on the XRD peaks. Three possibilities of nickel precipitate might occur, which are inclusion, occlusion, and adsorption. Inclusion is a co-precipitated impurity, whereas it occupies the lattice site. Second, occlusion happens due to physical adsorption of interfering ion and trapped between the precipitation 
processes. Rapid precipitation process or titration process might accommodate and ease the trapping process of nickel. Last is adsorption, whereas the impurity settled to the surface of the precipitates in a chemical or in a physical manner.

Table 2. Precipitates elements based on PLS

\begin{tabular}{|c|c|c|c|c|c|c|c|c|}
\multicolumn{7}{c|}{ Of $20 \% \mathrm{CaCO}_{3}$ addition } \\
\hline \multirow{2}{*}{$\mathrm{pH}$} & Area & \multicolumn{7}{|c|}{ Element (wt.\%) } \\
\cline { 3 - 9 } & & $\mathrm{O}$ & $\mathrm{A} 1$ & $\mathrm{~S}$ & $\mathrm{Ca}$ & $\mathrm{Mn}$ & $\mathrm{Fe}$ & $\mathrm{Ni}$ \\
\hline \multirow{3}{*}{1} & 1 & 42.13 & 1.34 & 25.16 & 9.07 & 1.26 & 19.03 & 2.00 \\
\cline { 2 - 9 } & 2 & 49.7 & 1.86 & 23.27 & 6.70 & 0.95 & 16.05 & 1.47 \\
\cline { 2 - 9 } & 3 & 35.88 & 1.69 & 28.51 & 3.02 & 1.51 & 27.61 & 1.78 \\
\hline \multirow{2}{*}{2} & 1 & 44.24 & 0.92 & 25.78 & 16.69 & 0.47 & 11.26 & 0.64 \\
\cline { 2 - 9 } & 2 & 32.99 & 1.76 & 29.78 & 14.96 & 0.83 & 17.77 & 1.90 \\
\cline { 2 - 9 } & 3 & 51.35 & 1.93 & 23.70 & 5.50 & 0.56 & 16.11 & 0.84 \\
\hline \multirow{3}{*}{3} & 1 & 47.55 & 1.01 & 22.89 & 15.30 & 0.49 & 12.30 & 0.46 \\
\cline { 2 - 9 } & 2 & 41.93 & 1.21 & 24.14 & 15.02 & 0.84 & 15.92 & 0.95 \\
\cline { 2 - 9 } & 3 & 15.73 & 1.28 & 30.47 & 9.5 & 1.68 & 38.31 & 3.03 \\
\hline
\end{tabular}

Table 3. Precipitates elements based on PLS of $25 \% \mathrm{CaCO}_{3}$ addition

\begin{tabular}{|c|c|c|c|c|c|c|c|c|}
\hline \multirow{2}{*}{$\mathrm{pH}$} & \multirow{2}{*}{ Area } & \multicolumn{7}{|c|}{ Element (wt.\%) } \\
\cline { 3 - 9 } & & $\mathrm{O}$ & $\mathrm{Al}$ & $\mathrm{S}$ & $\mathrm{Ca}$ & $\mathrm{Mn}$ & $\mathrm{Fe}$ & $\mathrm{Ni}$ \\
\hline \multirow{3}{*}{1} & 1 & 35.18 & 1.01 & 27.60 & 3.44 & 0.75 & 30.54 & 1.48 \\
\cline { 2 - 9 } & 2 & 48.02 & 1.40 & 26.12 & 0.45 & 0.73 & 22.31 & 0.97 \\
\cline { 2 - 9 } & 3 & 26.04 & 1.60 & 31.74 & 1.17 & 2.01 & 35.50 & 1.94 \\
\hline \multirow{3}{*}{2} & 1 & 47.18 & 1.69 & 25.07 & 8.85 & 0.51 & 15.23 & 1.48 \\
\cline { 2 - 9 } & 2 & 54.98 & 1.56 & 21.76 & 10.62 & 0.34 & 10.18 & 0.56 \\
\cline { 2 - 9 } & 3 & 48.95 & 2.24 & 25.47 & 3.53 & 0.59 & 18.07 & 1.15 \\
\hline \multirow{3}{*}{3} & 1 & 46.69 & 1.07 & 22.98 & 15.01 & 0.84 & 12.08 & 1.32 \\
\cline { 2 - 9 } & 2 & 43.24 & 0.87 & 24.62 & 19.39 & 0.91 & 9.82 & 1.15 \\
\cline { 2 - 9 } & 3 & 15.80 & 0.44 & 30.14 & 18.57 & 1.03 & 31.43 & 2.59 \\
\hline
\end{tabular}

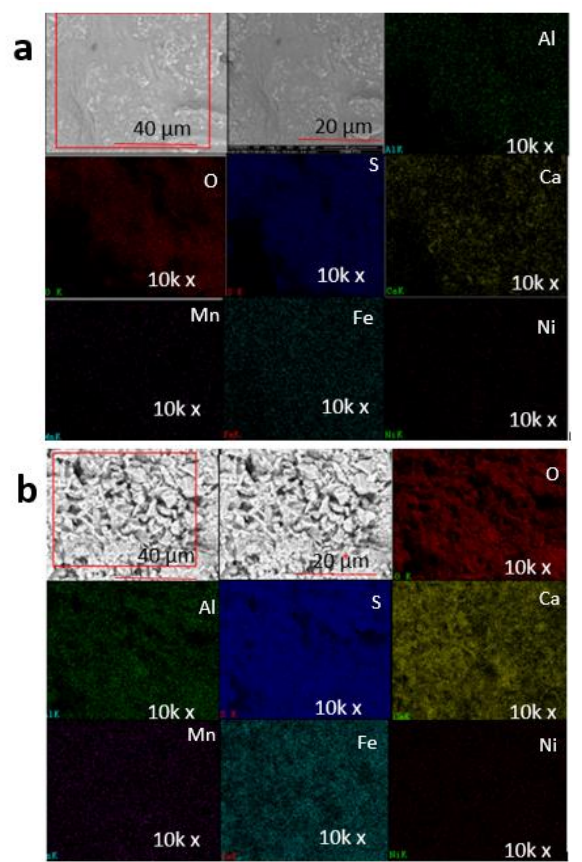

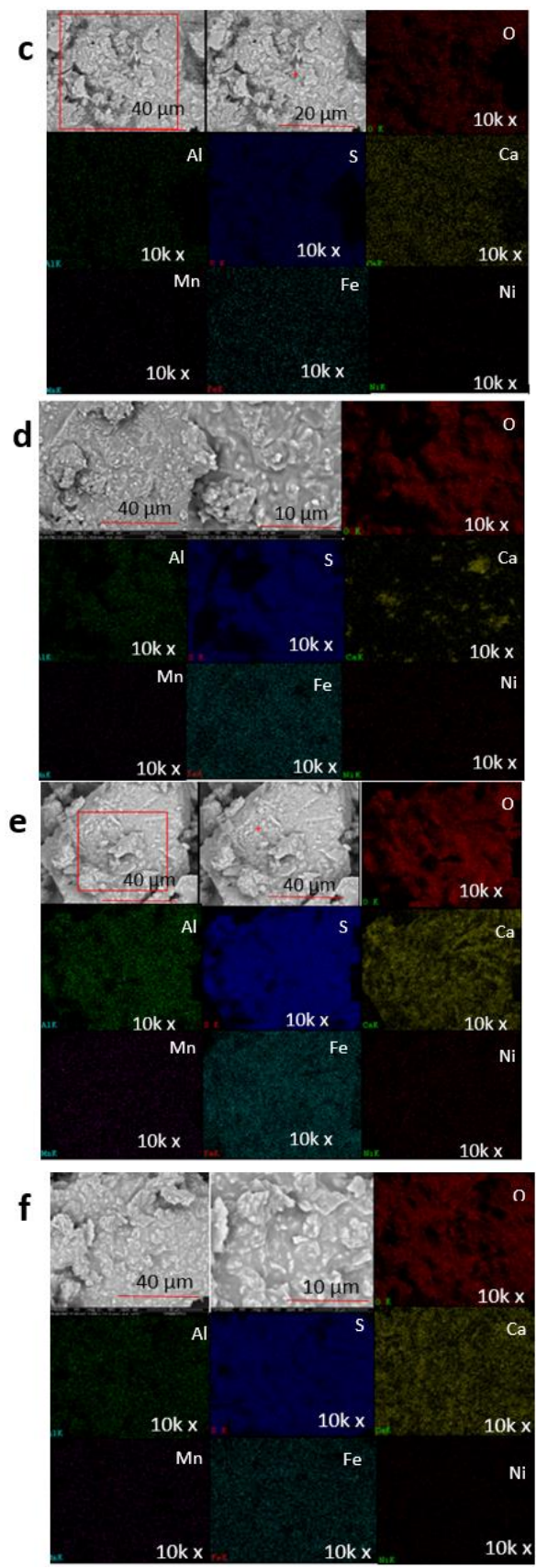

Figure 2. SEM-EDS elemental mapping of precipitates: (a) $20 \% \mathrm{pH} 1$ (b) $20 \%$ $\mathrm{pH} 2 \quad$ (c) $20 \% \mathrm{pH} 3$ (d) $25 \% \mathrm{pH}$ 1 (e) $25 \% \mathrm{pH} \quad 2$ (f) $25 \% \mathrm{pH} 3$

The elemental mapping demonstrates the presence of elements in the sample. Neutralization agents, such as $\mathrm{Ca}, \mathrm{S}$, and $\mathrm{O}$ are in a group of the cluster. The red cluster indicates oxygen, the blue cluster indicates sulfur and the yellow cluster indicates calcium which is dominant in the observation areas. On the other hand, metallic 
elements are more likely to form in separated form, which indicates the scarcity of the elements. A similar pattern is shown by $\mathrm{Fe}$ and $\mathrm{Al}$. However, for nickel, it is in separated or particle observation due to a small amount of this element and as the $\mathrm{pH}$ increase, the amount of cluster for the neutralization agents also increase. As additional information, the images show that as the $\mathrm{pH}$ increase, the filtrate becomes brownish and rustcolored looks like. The greenish color indicates the transformation into $\mathrm{Fe}(\mathrm{OH})_{2}$ and starts to precipitate at $\mathrm{pH}=7.5$. On the other hand, rustcolored $\mathrm{Fe}(\mathrm{OH})_{3}$ starts to precipitate at lower $\mathrm{pH}$ of $2 \mathrm{In} \mathrm{pH} 2$ until 3, the color changes into brown in the phase of $\mathrm{Fe}(\mathrm{III})$. The proportion of the $\mathrm{Fe}$ (II) and Fe (III) forms in solution is mainly due to the solution $\mathrm{pH}$ and $\mathrm{Eh}$ value or the Pourbaix Diagram (Safitri et al. 2018). From several studies, the possibility of the filtrates and precipitates is in the form of jarosite or/and goethite due to its yellow and brown color solution instead of red or hematite colored form (Vaughan, Hawker, and White 2011).

Table 4. Chemical composition of filtrate based on $20 \%$ and $25 \% \mathrm{CaCO}_{3}$ at varied $\mathrm{pH}$

\begin{tabular}{|c|c|c|c|c|c|c|}
\hline \multirow[b]{3}{*}{ Element } & \multicolumn{3}{|c|}{$20 \% \mathrm{CaCO}_{3}$} & \multicolumn{3}{|c|}{$25 \% \mathrm{CaCO}_{3}$} \\
\hline & $\mathrm{pH} 1$ & $\mathrm{pH} 2$ & $\mathrm{pH} 3$ & $\mathrm{pH} 1$ & $\mathrm{pH} 2$ & $\mathrm{pH} 3$ \\
\hline & $(\mathrm{mg} / \mathrm{L})$ & $(\mathrm{mg} / \mathrm{L})$ & $(\mathrm{mg} / \mathrm{L})$ & $(\mathrm{mg} / \mathrm{L})$ & $(\mathrm{mg} / \mathrm{L})$ & $(\mathrm{mg} / \mathrm{L})$ \\
\hline $\mathrm{Fe}$ & 3354.17 & 2765.36 & 3392.17 & 1968.27 & 2450.24 & 2512.63 \\
\hline $\mathrm{Ni}$ & 223.02 & 139.81 & 214.19 & 96.49 & 109.09 & 125.64 \\
\hline $\mathrm{Al}$ & 755.71 & 433.16 & 736.21 & 310.48 & 322.06 & 378.02 \\
\hline $\mathrm{Cr}$ & 184.78 & 116.41 & 177.06 & 76.05 & 88.91 & 100.94 \\
\hline $\mathrm{Mn}$ & 92.1 & 57.64 & 89.46 & 39.62 & 44.58 & 51.04 \\
\hline
\end{tabular}
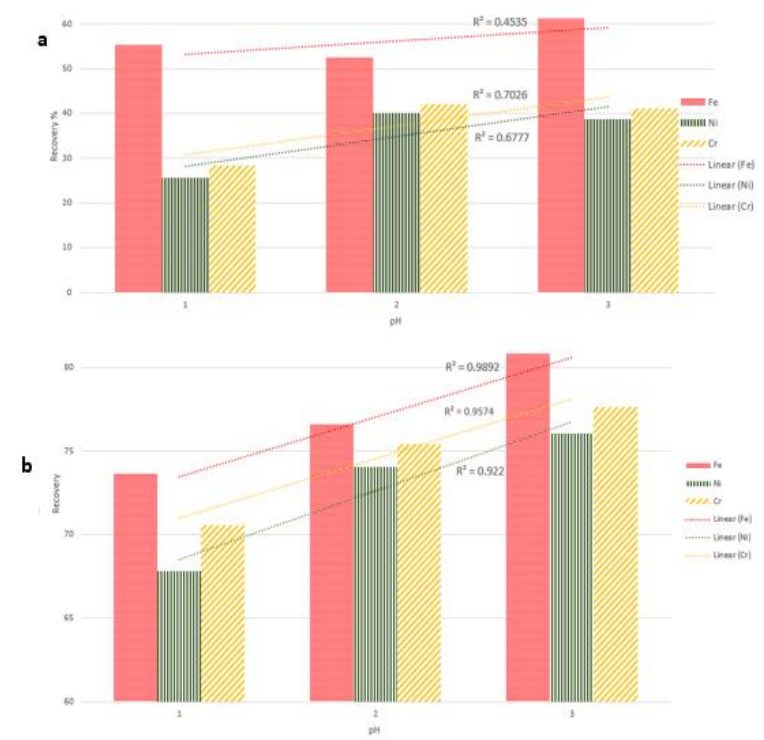

Figure 3. Filtrate Recovery for $20 \%$ (top) and $25 \%$ (bottom) $\mathrm{CaCO}_{3}$ at $\mathrm{pH} \mathrm{1,2}$ and 3
Filtrate is investigated by using ICP-OES to measure the amount of elements, especially iron, nickel, aluminum, chromium, and manganese. The chemical composition with a supporting recovery rate is shown in Figure 3 and listed in Table 4.

Figure 3 illustrates the number of recovery of the filtrate for $20 \%$ and $25 \% \mathrm{CaCO}_{3}$ at $\mathrm{pH} 1,2$, and 3 . The highest recovery recorded is the iron content; thus, the iron removal process has not been successfully achieved. All of the elements show a similar pattern. Therefore, the most efficient $\mathrm{pH}$ in concentration $20 \%$ is $\mathrm{pH} 1$. However, several studies reported that the optimum condition is $\mathrm{pH} 2$ at temperature is $90{ }^{\circ} \mathrm{C}$ (Köse and Topkaya 2011). The nickel composition is still in the high recovery rate and can be used for further nickel precipitation process.

\section{CONCLUSION}

The processing of nickel ore with a high amount of iron can usually be obtained by the hydrometallurgy process through acid leaching. However, lateritic ore consists a different kinds of elements, especially with high amount of iron; therefore, iron removal process must be done to eliminate the amount of iron to ease the process of nickel extraction later on in the precipitates form. In this study, the iron removal process is done by using a titration process of $20 \% \mathrm{w} / \mathrm{w}$ and $25 \% \mathrm{w} / \mathrm{w}$ of calcium carbonate alongside the changes of $\mathrm{pH}$ of 1,2 and $3,90^{\circ} \mathrm{C}$, and for 2 hours. Characterization and analyzing atmospheric leaching product are done through ICP-OES analysis specified for the filtrate and for the precipitates semi quantitative analysis and qualitative analysis are used to determine the phase created in the precipitates with the supporting elements on it by using SEM-EDS and XRD.

Further research is needed to investigated the overall process of the mixed hydroxide precipitates process regarding the iron removal stage 2, nickel precipitation, manganese removal and the creation of nickel-cobalt precursor. On the other hand, different parameters can be investigated to find greater efficiency. Afterward, hydrometallurgy process of nickel lateritic ore with sufficient amount of nickel can be processed 
in larger scale industry for related industries such as batteries and electric vehicles purposes.

\section{REFERENCES}

Bijih Nikel Tidak Boleh Diekspor Lagi per Januari 2020." 2019. Kementerian ESDM RI. https://www.esdm.go.id/id/mediacenter/arsip-berita/bijih-nikel-tidak-bolehdiekspor-lagi-per-januari-2020.

DiChristopher, Tom. 2018 "Electric Vehicles Will Grow from 3 million to 125 million by 2030, International Energy Agency Forecasts." CNBC-Energy.

https://www.cnbc.com/2018/05/30/electric -vehicles-will-grow-from-3-million-to125-million-by-2030-iea.html.

Haryadi, Harta. 2017. "Analisis Neraca Sumber Daya Pasir Besi dan Bijih Nikel Indonesia." Jurnal Teknologi Mineral dan Batubara 13 (2): 153-169.

Kamali-Heidari, Elham, Ata Kamyabi-Gol, and Abolghasem Ataie. 2018. "Electrode materials for lithium-ion batteries: a review." Journal of Ultrafine Grained and Nanostructured Materials 51 (1): 1-12.

Köse, C. H., and Y. A. Topkaya. 2011. "Hydrometallurgical processing of nontronite type lateritic nickel ores by MHP process." Minerals Engineering 24 (5): 396-415.

Mbedzi, N., Ibana, D., Dyer, L., \& Browner, R. 2017. "The effect of oxidant addition on ferrous iron removal from multi-element acidic sulphate solutions." In AIP Conference Proceedings, 1805. AIP Publishing LLC.

"Mineral Commodity Summary: Nickel Statistic and Information." 2020. U.S. Geological Survey.

Safitri, N., Mubarok, M. Z., Winarko, R., \& Tanlega, Z. 2018. "Recovery of nickel and cobalt as MHP from limonitic ore leaching solution: Kinetics analysis and precipitate characterization." In AIP Conference Proceedings, 1964. AIP Publishing LLC.

Solihin, Solihin. 2018. "Perilaku Pelarutan Logam Nikel dan Besi dari Bijih Nikel Kadar Rendah Sulawesi Tenggara." Metalurgi 29 (2): 139-144.
Vaughan, J., W. Hawker, and D. White. 2011. "Chemical aspects of mixed nickel-cobalt hydroxide precipitation and refining." In Proceedings of the ALTA $\mathrm{Ni} / \mathrm{Co} / \mathrm{Cu}$ Conference. 